\title{
BUSINESS STUDENTS' PERCEPTIONS OF ELECTRONIC COMMERCE - WILL THEY JOIN THE REVOLUTION?
}

\author{
Dieter Fink \\ School of Management Information Systems \\ Faculty of Business \\ Edith Cowan University \\ Pearson Street \\ Churchlands WA 6018 \\ AUSTRALIA \\ Fax 61-8-92738754, Telephone 61-8-92738726 \\ Email d.fink@cowan.edu.au
}

\begin{abstract}
The dramatic impact of Electronic Commerce (EC) is attracting much attention, most of which is directed towards emerging Intemet technology. However, it is generally acknowledged that it will take a few more years before EC becomes mainstream. The perceptions of business students, the future business leaders, on the promises and perils of EC are therefore vital. Our research indicated that they believe that the capabilities of the Internet for marketing and distribution are achieved to a greater extent than those for accounting and finance. The use of digital money appears to be still unrealistic in their opinion. Their main concem is for the insecurity of EC in such areas as computer viruses, theft of information, and unauthorised access to data by intruders. As a consequence, the trust the students currently have in EC is relatively low. However, they are optimistic about future prospects of EC, which they perceive will significantly improve over the next few years.
\end{abstract}

\section{INTRODUCTION}

The Internet has become an important medium for organisations desiring to interact with a wide range of stakeholders. It has the potential to market products and services to prospective customers, to communicate information to a global community, to provide an electronic forum for communications, and to process business transactions such as orders and payments (Nash et al., 1998). These activities have come to be known collectively as Internet or Electronic Commerce (EC) - the process of conducting commerce electronically over a variety of networks that constitute the Internet.

Through the use of digitisation, business transactions can be transmitted virtually instantaneously around the world. This has significant implications for international trade and the management of information as we move towards 2000. In the words of Buckeridge (1996, p 6), "The introduction of the new digital technologies elevates 'information' to its status as the predominant currency of postindustrial societies. This is eroding fixed notions of sovereign nation space, organisational structure, zones of production and marketing, and work processes."

Tapscott (1996) describes the 1990s as 'the age of networked intelligence'. He suggests that the decade be not simply about the networking of technology but about the networking of humans through technology. "It is not just an age of linking computers but of internetworking human ingenuity. It is an age of vast new promise and unimaginable opportunity." ( $x v)$ However, he also expresses a warning. "For individuals, organizations, and societies that fall behind, punishment is swift." ( $p$ xv)

\section{RESEARCH OBJECTIVE}

The effective exploitation of the Internet for EC is dependent on our ability to effectively manage a range of factors. These appear to be well recognised in literature, and include Information Technology (IT) and communications infrastructure, information security, application development tools, and EC management (Society for Information Management, 1997); reliability and privacy (Camp and Sirbu, 1997); and network bandwidth and security (Sim and Rudkin, 1997).

While much attention is currently being devoted to solving technological challenges, for example increasing the bandwidth on existing narrowband network platforms to overcome bottlenecks (Buckeridge, 1996), no or little attention appears to be given to the human aspects of EC. This has been a mistake in the past as human resistance to, or incompetence during, the introduction of new IT often caused information systems (IS) to fail (Sauer, 1993; Beynon-Davies, 1995). By focusing on the human elements early in the adoption of EC technology, we have the opportunity to avoid the mistakes made in the past.

In this paper we examine the attitudes of business students to Electronic Commerce in order to establish their perceptions of the promises and perils of this new technology. The reason for choosing young persons was that it will take a few more years, ".. certainly not before the year 2000 - before Internet electronic commerce is in the mainstream of the global economy. And it will take at least another decade after that before it becomes a truly significant factor in terms of total commerce" Stuck (1996, p 54). By then the current crop of business students 
will play a major role in the new ways of doing business. They will have been associated with EC from the ground level up.

\section{RESEARCH VARIABLES AND HYPOTHESES}

In this research we examined the perceptions of business students on the promises and perils of EC. The variables comprised EC capabilities, in particular those of marketing/distribution and accounting/finance, and associated concerns and risks. They are discussed below together with our hypotheses.

\section{Electronic Commerce Capabilities}

The use of the Internet has the potential to cover most, if not all, phases of marketing and distribution and accounting and finance. For example, with the former, product discovery is facilitated through product information (e.g. catalogues) being dispersed on Web pages. With the latter, funds can be transferred electronically to anywhere in the world. These activities are explored in more detail in the following sections.

EC also has the capability of providing continuous service by offering access to information around the clock and globe in multiple languages. Administration processes can be automated to a larger extent than before; for example customers can submit their orders online with no clerical intervention and receive payments by a direct transfer of funds to their bank account.

At present, the literature deals mainly with marketing and distribution activities occurring on the Internet. We sought to confirm this impression by framing our hypothesis as follows:

Hypothesis 1: In the use of the Internet for electronic commerce, its marketing and distribution capabilities are achieved to a greater extent than its other capabilities.

\section{MARKETING AND DISTRIBUTION}

The marketing and distribution capabilities of EC broadly fall into 2 major areas (Stuck, 1996). First, EC enables buyers to enquire about products and services, place orders and receive goods and services online. Second, EC enables sellers to advertise products and services, and deliver goods and services electronically and provide ongoing customer support.

Product discovery is facilitated through product information being dispersed on Web pages and by targeting a special interest group, such as wine buffs. This has benefited smaller firms in particular because they can now provide their products to niche markets anywhere in the world, unconstrained by economies of scale. However, the way in which products can be delivered on the Internet is determined by the degree to which the physical product can be transformed into a digital product. Information products, including computer software, are the most obvious commodities for EC. The Internet is not well suited for the distribution of those goods that typically require physical or tactical sampling, such as furniture and fresh food (Woods, 1996).

At present the communications capabilities of the Internet appears to attract the most attention and we are witnessing an explosion in Web sites. We, therefore, hypothesised as follows:

Hypothesis 2: In the use of the Internet for marketing and distribution, its communications capabilities are achieved to a greater extent than its other capabilities.

\section{ACCOUNTING AND FINANCE}

While banks and organisations have used Electronic Fund Transfer (EFT) to settle business transactions for many years, this has been done in a highly controlled manner. The Internet has the potential to allow the free flow of funds between millions of Internet subscribers. However, developments towards secure electronic cash (digital cash) have not reached a sufficient level of maturity (Forcht and Wex, 1996; Liddy, 1996) and most Internet payments continue to rely on the use of credit cards.

The Internet has provided the capability to substantially reduce accounting and financial transaction costs as illustrated by the example of electronic banking. The introduction of new technology has the potential to reduce the cost of banking significantly. To serve a customer over the counter is far more expensive than to serve him or her through Automatic Teller Machines (ATMs) which in turn is more costly than conducting customer transactions electronically on the Internet.

At present, electronic payments systems are constraint because of the reliance on credit cards rather than the use of digital cash. We, therefore, framed the following hypothesis: 
Hypothesis 3: In the use of the Internet for accounting and finance, its data processing cost reductions capabilities are achieved to a greater extent than its other capabilities.

\section{CONCERNS}

Most literature on EC acknowledges that the promises of the technology are currently being constrained by their perils, be they real or perceived. As with the introduction of all new technologies, users have a variety of concerns that they need to weigh up when deciding whether or not to adopt Internet technology (Arnum, 1995). Concerns relate to the apparent insecurity of the Internet, potential disruption to business because of network failure, the lack of businesses partaking in EC, possibly caused by high setup and running costs, and slow performance (e.g. data transfer) due to inadequate bandwidth (Nath et al., 1998). Furthermore, there appears little overall control because universal standards and legislature have not developed sufficiently (Pattison, 1997). It is generally acknowledged that security is holding back the full exploitation of the Internet's capabilities. We, therefore, hypothesised as follows:

Hypothesis 4: In the use of the Internet for electronic commerce, the concern for security is perceived to be greater than other concerns.

\section{Risks}

Essentially two types of risk factors can be identified for the Internet, namely business risks and technology risks (Matinez, 1996). The former relate to products and services ordered on the Internet not being of the quality promised, not being delivered even though they have been paid for, or the buyer denying having placed the order. Legal uncertainty provides further risk in relation to what constitutes an offer and acceptance on the Internet, how do the copyright provisions work, and where does the jurisdiction exist when trade spans the globe (Pattison, 1997).

Technological risks include computer viruses, introduced through data obtained from the Internet, and hacker attacks penetrating computer system in an unauthorised manner for the purpose of causing damage (e.g. introducing a virus) and stealing valuable information. Furthermore, all data and messages being forwarded to and from the Internet are potentially subject to interception and modification while being transmitted (Forcht and Wex, 1996; Liddy, 1996).

Adverse publicity relating to security breaches on the Internet (e.g. the disclosure of credit card information The Weekend Australian, 23-24 November 1996), caused us to believe that users of the Internet are mostly concerned with the security of information. Hence, we framed the following hypothesis:

Hypothesis 5: In the use of the Internet for electronic commerce, the risk of theft of valuable information is perceived to be greater than other risks.

\section{RESEARCH CONDUCT}

In our study, we used final-year university student as surrogates for young business persons. This approach has been used successfully in past studies, for example in advertising and marketing research (Yavas, 1994) and technology evaluation (Briggs et al., 1996). The students were completing the final year (1997) of a three-year Bachelor of Business degree in the Faculty of Business at Edith Cowan University (ECU) in Perth, Western Australia. Seventy-five students voluntarily completed a questionnaire that captured their opinions on various issues related to the current and future use of the Internet for EC.

The primary research question was: do business students perceive the Internet as a suitable vehicle for conducting commerce? This was reflected in the preceding hypotheses that aimed to establish to what extent are EC capabilities being met and what are the concerns and risks associated with EC. When phrasing the variables we endeavoured to use terminology familiar to the participating students. For example, the capability of the Internet to automate administration was illustrated by referencing the system allowing students to enroll themselves over the Internet at ECU.

The students belonged to 3 equal groupings of 25 each reflecting their major study, namely Accounting, Marketing, and Information Systems. The questionnaire was relatively short and captured the participants' opinions on a 7-item rating scale. The experiences of the participating students with the use of the Internet are shown in Table 1. 
Table 1:Experience in using the Internet

("1 Extremely Low - 7 Extremely High")

\begin{tabular}{ccc}
\hline Discipline & At this moment & In 1-2 years time \\
\hline Accounting & 3.75 & 5.33 \\
Marketing & 3.60 & 5.36 \\
Information Systems & 4.84 & 6.04 \\
Overall & 4.06 & 5.57 \\
\hline
\end{tabular}

Information systems students, as could be expected, indicated the highest levels of experiences, currently and in the near future. The experiences of those belonging to the other two disciplines were lower and close to each other. A definite upward trend over the next 1-2 years is apparent for all three disciplines.

\section{RESEARCH FINDINGS}

The study began by establishing the perceptions of business students on the broad capabilities of EC; they are shown in Table 2.

Table 2: Broad Capabilities of EC

("1 Not Achieved - 7 Fully Achieved")

\begin{tabular}{lr}
\hline & Mean \\
\hline $\begin{array}{l}\text { Marketing and distribution (e.g. product information is provided on } \\
\text { the Net) }\end{array}$ & 4.72 \\
$\begin{array}{l}\text { Providing continuous service (e.g. information is provided around } \\
\text { the clock) }\end{array}$ & 4.66 \\
$\begin{array}{l}\text { Finance and accounting (e.g. transferring funds electronically } \\
\text { around the world) }\end{array}$ & 3.91 \\
$\begin{array}{l}\text { Automating administration (e.g. students enrolling themselves over } \\
\text { the Net) }\end{array}$ & 2.56 \\
\hline
\end{tabular}

As seen from Table 2, business students supported our hypothesis that the Internet currently achieves marketing and distribution activities to a greater extent than other activities. The t-test indicated that 'marketing and distribution' capabilities were, however, not significantly rated higher than 'providing continuous service' ( $t=$ $.34, p>.05)$. They were rated significantly higher than 'finance and accounting' $(t=4.16)$ and 'automating administration' $(t=-9.58)$ at $p<.05$. Our hypothesis $1 \mathrm{can}$, therefore, be partially accepted.

The study proceeded by requesting participants to rate the marketing and distribution capabilities of EC: they are shown in Table 3.

Table 3: Marketing and Distribution Capabilities of EC

("1 Not Achieved - 7 Fully Achieved")

\begin{tabular}{lr}
\hline & Mean \\
\hline $\begin{array}{l}\text { Distribution of samples (e.g. enabling software to be downloaded } \\
\text { for a free trial) }\end{array}$ & 5.25 \\
$\begin{array}{l}\text { Provision of online feedback from customers and prospects (e.g. via } \\
\text { email) }\end{array}$ & 4.97 \\
$\begin{array}{l}\text { As another communications media (e.g. like press, TV, radio) } \\
\text { To target specific interest groups (e.g. potential home buyers, wine }\end{array}$ & 4.81 \\
$\begin{array}{l}\text { buffs) } \\
\text { To sell well-known brand products (e.g. golf balls) }\end{array}$ & 4.53 \\
$\begin{array}{l}\text { Allows smaller firms access to niche markets (e.g. enabling product } \\
\text { discovery) }\end{array}$ & 4.46 \\
$\begin{array}{l}\text { As a shopfront for goods requiring physical sampling (e.g. furniture, } \\
\text { fresh foods) }\end{array}$ & 4.45 \\
\hline
\end{tabular}

As seen from Table 3, the capabilities of the Internet as a 'communications media' was not rated the highest as predicted in the hypothesis. Rather this capability rated third highest behind the capabilities of 'distribution of 
samples' and 'provision of online feedback from customers and prospects'. The t-test indicated that the rating difference with the highest rated item $(t=-2.02)$ was statistically significant at $p<.05$ (this was not true with the second highest rated item $(t=-1.02))$. Our hypothesis 2 , therefore, had to be rejected.

Table 4 reflects the perceptions of the participants of how well accounting and finance capabilities are currently being met by EC.

Table 4: Accounting and Finance Capabilities of EC

("1 Not Achieved - 7 Fully Achieved")

\begin{tabular}{lr}
\hline & Mean \\
\hline Reducing data processing costs through greater automation & 4.21 \\
Transferring funds electronically to anywhere in the world & 4.09 \\
Being able to use 'digital money' & 3.57 \\
\hline
\end{tabular}

As predicted, 'data processing cost reduction' capabilities were rated the highest. However, the t-test revealed that this was only significant compared to the 'use of digital money $(t=-3.84)$ but not compared with 'transferring funds electronically' $(\mathrm{t}=-.80)$ at $\mathrm{p}<.05$. Our hypothesis 3 can, therefore, be partially accepted.

The major concerns associated with EC are shown in Table 5.

Table 5: Concerns with EC

("1 Extremely Unconcerned - 7 Extremely Concerned")

\begin{tabular}{lr}
\hline & Mean \\
\hline Security (e.g. potential for data interception) & 5.68 \\
Legislature (e.g. lack of privacy protection) & 5.13 \\
Confidence (e.g. lack of universal standards) & 5.05 \\
Reliability (e.g. breakdown of the Net) & 4.89 \\
Performance (e.g. data transferred to slowly) & 4.86 \\
Connections (e.g. lack of businesses connected) & 4.59 \\
Setup and running costs & 4.54 \\
\hline
\end{tabular}

Security concerns were rated highest as hypothesised. Furthermore, t-tests revealed mean differences between this concern and all others to be significant at $p<.05$. Our hypothesis 4 can, therefore, be accepted.

Table 6 provides the perceptions of specific EC risk factors.

Table 6: Risks of EC

("1 No Risk - 7 Extreme Risk")

\begin{tabular}{lr}
\hline & Mean \\
\hline Computer viruses being introduced through data obtained from the & 5.58 \\
Net & \\
Theft of valuable information (e.g. credit card details) & 5.43 \\
Unauthorised access to data by intruders such as hackers using the & 5.20 \\
Net & \\
$\begin{array}{l}\text { Goods/services ordered on the Net not being of the quality } \\
\text { promised }\end{array}$ & 4.93 \\
$\begin{array}{l}\text { Uncertainty of using digital money (e.g. money 'disappears', is } \\
\text { 'duplicated') }\end{array}$ & 4.93 \\
$\begin{array}{l}\text { Interception and modification of data while being transmitted } \\
\text { electronic medium as evidence) }\end{array}$ & 4.91 \\
Goods/services ordered and paid for on the Net not being delivered & 4.91 \\
\hline
\end{tabular}

Our prediction that the risk of 'theft of valuable information' would be rated highest was not realised; it followed the risk of 'computer viruses being introduced' in the ranking of risk factors. However, through t-tests it was established that the ratings of these two items were statistically not significantly different $(t=-1.15)$ at $p<.05$. Compared with other risk factors, 'theft of valuable information' was also not statistically significantly different 
from 'unauthorised access to data'; however it differed significantly from all other factors at $p<.05$. Our hypothesis 5 can, therefore, be partially accepted.

The students came from 3 backgrounds determined by the studies they were pursuing, namely accounting, marketing and information systems. According to the Analysis of Variance (ANOVA) statistical procedure, few differences existed between the groups as to their perceptions and experiences of EC. Those of statistical significance are reported in Table 7 below.

Table 7: Inter-disciplinary Difference in Perceptions of EC

\begin{tabular}{|c|c|c|c|c|c|}
\hline & $\begin{array}{l}\text { Sum of } \\
\text { Squares }\end{array}$ & $\mathrm{df}$ & $\begin{array}{l}\text { Mean } \\
\text { Square }\end{array}$ & $\mathrm{F}$ & Sig. \\
\hline \multicolumn{6}{|c|}{$\begin{array}{l}\text { Marketing \& Distribution: to } \\
\text { provide online feedback }\end{array}$} \\
\hline Between Groups & 10.788 & 2 & 5.394 & 3.862 & $.026 *$ \\
\hline Within Groups & 99.158 & 71 & 1.397 & & \\
\hline Total & 109.946 & 73 & & & \\
\hline \multicolumn{6}{|c|}{ Concerns: security } \\
\hline Between Groups & 12.253 & 2 & 6.127 & 3.763 & $.028 *$ \\
\hline Within Groups & 115.598 & 71 & 1.628 & & \\
\hline Total & 127.851 & 73 & & & \\
\hline \multicolumn{6}{|c|}{ Concerns: reliability } \\
\hline Between Groups & 12.510 & 2 & 6.255 & 3.622 & $.032 *$ \\
\hline Within Groups & 122.625 & 71 & 1.727 & & \\
\hline Total & 135.135 & 73 & & & \\
\hline \multicolumn{6}{|c|}{$\begin{array}{l}\text { Experience: at this moment in } \\
\text { time }\end{array}$} \\
\hline Between Groups & 22.802 & 2 & 11.401 & 4.133 & $.020 *$ \\
\hline Within Groups & 195.860 & 71 & 2.759 & & \\
\hline Total & 218.662 & 73 & & & \\
\hline
\end{tabular}

${ }^{*} \mathrm{p}<.05{ }^{* *} \mathrm{p}<.001$

Disciplinary differences existed in respect of perceptions as to capability of the Internet to provide online feedback, concern over the security and reliability of EC, and current Internet experience levels. The findings are discussed further on in the paper.

As indicated in the paper's introduction, it is expected that EC activities will evolve over the next few years. This prediction appears to be reflected in the students' perceptions of EC prospects as shown in Table 8.

Table 8: Prospects for EC

("1 Extremely Poor - 7 Extremely Good")

\begin{tabular}{lr}
\hline & Mean \\
\hline In near-term (1-2 years) & 4.72 \\
In medium term (3-5 years) & 5.48 \\
In long-term ( $>5$ years) & 6.13 \\
\hline
\end{tabular}

The prospects for EC are perceived as getting increasingly better. T-Tests show that ratings improve significantly from the near term to the medium term $(t=-6.39)$ and to long term $(t=-7.23)$, and from medium term to long term $(t=-6.01)$ at $p<.05$.

\section{DISCUSSION}

Our research indicated that business students perceived greater benefits in the current use of the Internet for marketing and distribution than for accounting and finance purposes. They indicated through relatively high ratings that various marketing and distribution capabilities of $\mathrm{EC}$ are reasonably well met at present, particularly in the distribution of digital goods, such as software, and enabling online feedback from customers and prospect. Other activities highly rated were the use of the Internet as a communications media and the ability to target specific interest groups. 
Accounting and finance capabilities are currently not as highly rated than marketing and distribution. While acknowledging that IT costs are being reduced and funds are successfully being transferred electronically, the study participants did not perceive that the use of digital money is currently being achieved. For digital money to become the norm it has to achieve true interoperability, i.e. money must be in a specific form and widely used as a standard or readily convertible to a standard form (Camp and Sirbu, 1997). The lack of assurance that the above requirements can presently be met appears to be holding back the adoption of digital money.

The greatest concern is the security of EC. This is understandable when one considers the workings of EC. When information is sent over the Internet, it is split into small data packets that are transmitted over shared communication lines to their destination. The sender has no control over the route that data takes or that messages are not being tampered with. Even though security measures exists (e.g. encryption), they are not universally accepted as providing a failsafe environment. For example, "Mass retail applications that rely on credit cards for payments are not amenable to encryption, even though they are among the transactions that most need protection from hackers." (Arnum, 1995, p 36) Furthermore, "Message tracing, tracking, delivery receipts and acknowledgments- standard features of a private EDI network service - are still unknown to the Internet" (Arnum, 1995, p 37).

Risk factors were generally rated high. Those of a technological nature were rated higher than those of a business nature. For the person receiving data there is the risk that the files downloaded contain damaging computer viruses. Furthermore, with the use of an extended network, the potential for unauthorised persons (hackers) to access and cause damage to data increases substantially. It is possible that private or confidential information, such as credit card information, is intercepted during transmission. Among business risk rated highly is the risk that goods and services ordered on the Internet are not of the quality promised.

An examination of the mean ratings to establish inter-disciplinary differences showed that marketing students rated the ability of the Internet to provide online feedback from customers and prospects far lower than the accountants and information systems students. This is of concern since the capability of the Internet to establish a direct link to customers and others is regarded as a very significant marketing advantage (Ghosh, 1998). Furthermore, the technology used to maintain electronic contact (e.g. email) is mature and reliable.

Concern over the security of EC was significantly lower among accounting compared to marketing and information systems students. This is surprising since accountants are generally trained to be security aware and adopt a more conservative attitude to business than other disciplines. However, their concern is at a high level and it can reasonably be expected that the prospects of conducting financial transactions over the Internet will remain relatively low unless their security concerns can be overcome.

Information systems students expressed greater concern over the reliability of EC than accounting and marketing students. Their concerns are important because they appeared to possess significantly higher current experiences with EC than their fellow students. In business organisations, it is common that information systems professionals are asked to provide assurance on the reliability of systems; if they are concerned it is less likely that other disciplines will be inclined to take-up the new technology.

\section{IMPLICATIONS}

The research indicated that the current experience with EC among final year business students was not very high. On a scale of 1 (extremely low) and 7 (extremely high), information systems students rated their experience as 4.84 , those in accounting as 3.75 , and for marketing it was 3.60 . The new generation of business persons as well as educators need to recognise that greater emphasis should be placed on obtaining and providing training and experience in the areas of EC. "For better or worse, Electronic Commerce will not be an elective course for most senior managers- it has become part of the core curriculum." (Frank, 1997, p 37)

To be able to exploit and manage EC effectively, business persons have to be taught that EC applications are business systems and not just computer systems. Whilst EC activities include the traditional elements of computer processing and technology, their impact is also felt in the areas of business strategy, customer-supplier relations, business processes and people. All these elements have to be managed in an integrated and holistic manner. According to Daniels (1994), future business will act as if no boundaries exist, cross-functional networks will replace functional organisation structures, and the organisation will develop cultures that fit into any country. The ability of business executives to manage change will be more important than ever before.

Furthermore, EC is an inter-disciplinary activity which should not be delegate to the information systems (IS) or marketing groups. While IS professionals have become more business oriented through their involvement in inter-organisational systems and business process re-engineering they cannot replace the business executive's strategic expertise. They most likely will continue to place emphasis on technology issues. The marketing group, on the other hand, has a strong business orientation but generally lacks technological expertise. EC offers marketing the opportunity to foray into the IS domain and IS to interact more significantly with other business disciplines. 


\section{LIMITATIONS AND CONCLUSION}

One limitation of the study is that not much information was captured about the characteristics of the respondents, in particular their knowledge and types of experiences with the Internet and EC. For example, the extent of their knowledge was not assessed by the nature of the units they had completed on this topic during the course of their study and the academic results they had obtained. This made it difficult to provide detailed explanations and recommendations on how their perceptions about EC were formed and could be changed.

Another limitation concerns the few differences found between the business disciplines being studied by the respondents as reported in Table 7. These may have been due to chance and their interpretation contained in the discussion section is therefore of a tentative nature only. Furthermore, it is not possible to discover more definite reasons for the differences in perceptions between the three student groupings without additional information background information of the nature highlighted in the preceding paragraph.

In conclusion, the success or failure of EC will be determined by the trust that people show towards the use of Internet technology. In other words, they will weigh up their perceptions of the capabilities of EC against perceived concerns and risks. Our study indicated that business students believe that the capabilities of EC are not currently fully achieved and that high levels of concerns and risks exist. However, they hold high hopes for its future prospects which appear to be very good in both the medium (3-5 years) and long-term (over 5 years). This means that EC is expected to dramatically increase, thereby bringing about a paradigm shift in the way business will operate. Business leaders of the future are advised to prepare themselves for the changes ahead.

\section{REFERENCES}

Arnum E. (1995) "Doing Business on the Internet - A Question of Balance", Business Communications Review, August, pp 35-37.

Briggs R.O., Balthazard P.A., \& Dennis A.R. (1996) "Graduate Business Students as Surrogates for Executives in evaluating of Technology", Journal of End User Computing, 8(4), pp 11-17.

Buckeridge R. (1996) "Winning the Cyberspace Race", IT Chapter, Spring, pp 6-7.

Camp L.J. and Sirbu M. (1997) "Critical Issues in Internet Commerce", IEEE Communications Magazine, May, pp 58-62.

Daniels N.C. (1994) Information Technology: The Management Challenge, Addison-Wesley Publishing Company, Wokingham.

Forcht K.A. \& Wex R. (1996) "Doing Business on the Internet: Marketing and Security Aspects", Information Management \& Computer Security, 4(4), pp 3-9.

Frank M. (1997) "The Realities of Web-Based Electronic Commerce", Strategy Leadership, May/June, pp 3137.

Ghosh S. (1998) "Making Business Sense of the Internet", Harvard Business Review, March-April, pp 126135.

Liddy C. (1996) "Commercial Security on the Internet", Information Management \& Computer Security, $4(1), \mathrm{pp} 47-49$.

Martinez A. (1996) "What Risk Managers should know about the Internet", Risk Management, 43(11), pp 4346.

Nath R., Akmanligil M., Hjelm K., Sakaguchi T., \& Schultz M. (1998) "Electronic Commerce and the Internet: Issues, Problems, and Perspectives", International Journal of Information Management, 18(2), pp 91101.

Pattison M. (1997) Legal Implications of Doing Business on the Internet, Information Management \& Computer Security, 5(1), pp 29-34.

Sim S.P. \& Rudkin S. (1997) "The Internet - Past, Present and Future", BT Technology Journal, 15(2), pp 1123.

Society for Information Management (1997) "Electronic Commerce: The Work is just Beginning", Software Magazine, 17(1), pp 102-106.

Stuck B.W. (1996) "Internet Transactions Still Yield Small Change", Business Communications Review, July, pp 51-54.

Tapscott D. (1996) The Digital Economy, McGraw-Hill, New York.

Wood R. (1996) "Doing Business on the Internet", IT Chapter, Spring, pp 4-5.

Yavas U. (1994) "Research note: Students as Subjects in Advertising and Marketing Research', International Marketing Review, 11(4), pp 35-43. 